\title{
Belonging to Multiple Nationalities: A Phenomenological Study
}

\author{
Annette Peters \\ University of Northern Colorado \\ Basilia Softas-Nall \\ University of Northern Colorado \\ Megan Martinez \\ University of Northern Colorado
}

\begin{abstract}
The purpose of this qualitative study was to explore the lived experiences of individuals who identify with multiple nationalities. As the world becomes increasingly global and more individuals migrate, it is becoming commonplace for individuals to identify with more than one nationality. Psychologists and mental health professionals need to be aware of the impact of having multiple nationalities integrated into one's identity in order to gain a deeper understanding and provide more effective treatment to these individuals. A phenomenological research design was utilized in this study. Ten participants identifying with more than one nationality (age range $\mathbf{= 2 5}$ to $46, \bar{x}=30.1$ ) were interviewed. Several themes emerged within a context of intersectionality including: (a) process of constructing a multiple nationality identity; (b) intentionality about identifying with multiple nationalities; (c) reactions of others; (d) cultural intelligence-openness, appreciation, and acceptance of diversity; (e) similarities between cultures, language, religions, and spiritualties across nationalities; (f) feeling connected or disconnected through language; (g) where is home, and where do I belong?; (h) professional identities; and (i) importance of food. Participants provided recommendations for mental health professionals. Theoretical, research, and clinical implications are discussed.
\end{abstract}

Keywords: Identity, intersectionality, phenomenology, nationality

Due to globalization, better transportation, and communication networks people have been able to cross national borders with greater ease than ever before (Casas, Park, \& Cho, 2010). The ability to move increases the likelihood people will identify with multiple nationalities. In the United States alone, about $13 \%$ of the population resided in a different country before immigrating to the United States, and about $85 \%$ of these individual speak a language other than English at home (U.S. Census, 2010). The internalization of multiple nationalities, speaking more than one language, living in a multicultural community, and cross-cultural marriages all can lead to the development of a multicultural identity. As the world becomes increasingly global and we encounter culturally diverse clients, we must understand each client's situation in order to provide culturally responsive counseling. For this reason, the process of making sense of multiple nationalities is an important area of research.

National identity is a multifaceted concept and can be considered a combination of a person's birth, ancestry, accent, and residence (Hadley, 2004). National identity may be more important for some individuals and the strength of one's sense of national identity is impacted by a number of factors, including income, privilege, and the ethnic makeup of a country (Masella's, 2013). In the field of psychology, nationality has been largely neglected, potentially due to the 
field being dominated by the U.S. (Platt \& Laszloffy, 2013). "Given the power and privilege that the United States has in relation to other nations, it can be difficult for those who are from the United States to recognize how their nationality shapes their values, beliefs, and behaviors and to recognize the privilege and ensuing benefits that their nationality affords them" (Platt \& Laszloffy, 2013, p. 442).

Identity continues to develop and change throughout life. Identity encompasses a sense of one's goals, beliefs, values, and life roles (Erikson, 1950; Marcia, 1987). The development of identity is dynamic and calls for continual assessment and exploration of one's sense of self. Changing environments and developmental changes can influence identity. A person has multiple senses of self that are composed of various salient identities such as one's cultural, national, ethnic, gender, religious, and spiritual identities. According to intersectionality theory, it is important to consider how these various identities interact to impact one's sense of self, especially because each identity does not account for the whole person (Hancock, 2007; Oleksy, 2011). Intersectionality deepens the understanding of humans by providing a rich, holistic description of how people make sense of their various identities. It is an attempt to understand the various dimensions of the individual. Psychologists must understand intersectionality to be culturally competent, social justice advocates and to better understand the individuals they aim to help in a richer context.

Due to the scarcity of literature on individuals identifying with multiple nationalities, researchers attempted to gain a better understanding of how a person's national identity influences beliefs, behaviors, and presenting issues related to mental health. Current psychologists are emphasizing the importance of becoming culturally competent psychologists and social advocates. Importantly, McGoldrick, Giordano, and Garcia-Preto (2005) discussed how becoming culturally competent requires us to question dominant values and investigate the complexity of cultural identity. Understanding these concepts would contribute to both international psychology and mental health services.

The purpose of this phenomenological study was to explore the lived experiences of individuals who identify with more than one nationality in the context of intersectionality. The overall goal was to capture the essence of how these individuals construct a sense of identity.

\section{METHOD}

Researchers employed phenomenological methodology to explore the essence of participants' experiences. When conducting phenomenological research, "the researcher is intimately connected with the phenomenon" (Moustakas, 1994, p. 59) and, simultaneously, the researcher must be intentional about setting aside their own biases and prejudgments. The assumption, when working within a phenomenological framework, is that individuals who experience the same phenomenon have a shared essence of experience and these core meanings are mutually understood. With regards to epistemology, the current research was approached from a constructionist perspective, which asserts that people construct and that there are several, equally valid realities (Crotty, 1998), to allow participants to construct their own meaning and truths about the phenomenon of identifying with more than one nationality. Constructivism assumes that reality is socially constructed, and thus individuals make sense of themselves through their interactions with the environment.

The current research aimed to answer the following research question: Q1. What are the lived experiences of individuals identifying with more than one nationality in the context of 
intersectionality? There were also two additional subquestions, including: Q1a. How have individuals made sense of themselves when identifying with more than one nationality? And Q1b. What has facilitated or hindered these individuals' identity development?

\section{Participants}

\section{PROCEDURE}

The current study used criterion sampling, as recommended by Creswell (2007), for selecting participants for phenomenological studies. Criterion sampling is utilized by identifying specific criteria in order to screen participants. It ensures all participants have experienced the phenomenon, firsthand rather than secondhand, which is essential to the phenomenological paradigm (Creswell, 2007). Participants were 10 individuals who identified with more than one nationality (see Table 1 for demographics). There are several important criteria that aided in selection of participants. First, participants were required to identify with more than one nationality, either through birth or migration. Additionally, all participants were purposely chosen to be at least 24 years old. These criteria were included for the following reasons: (1) Individuals will have gone through Erikson's stage of identity versus role confusion and (2) Mid-twenties has been identified as the age where society sees individuals as early adults and expects mature adult-like behaviors (Winefield \& Harvey, 1996). Participants in the current study ranged in age from 25 years old to 46 years old, with a mean age of 30.1. Participants were screened to ensure they understood and spoke English at a sufficient level to participate, which prevented potential problems with translation and transcription. Furthermore, participants were required to have access to a computer with Skype ${ }^{\mathrm{TM}}$. Skype ${ }^{\mathrm{TM}}$ embodies more the face-to-face dynamics of traditional interviewing because, unlike telephone interviewing, it has a visual component (Hanna, 2012).

In order to recruit participants, researchers contacted several locations in North America and Europe, requesting them to send the recruitment letter to their members. Furthermore, snowball sampling, where participants are asked to recommend other, similar participants, was utilized in order to obtain information rich-cases. For the current study, saturation, "operationalized as collecting data until no new information is obtained" (Morse, 1995, p. 147), was reached after the seventh person. Three more individuals already recruited were interviewed to continue gathering information on unique experiences as well as verify the information gathered from the first 7 participants. As Polkinghorne (2005) recommends 5 to 25 participants for phenomenological research, the current sample of 10 is adequate.

The primary researcher kept a participant journal, in which she documented known demographics of individuals who were interested in participating in the study and the decision making process undergone for inclusion. Twenty individuals contacted researchers with initial interest in participating. Ten of these twenty individuals participated. Seven participants were excluded because they did not meet all inclusion criteria. Three individuals withdrew due to not being able to commit to more than one interview. One of these three individuals completed part of the first interview but was unable to finish the interview. Therefore, his information was not included.

\section{Data Collection}

Data consisted of two or three 60-to-90- minute semi-structured interviews (see Appendix 2), which included demographic information, and brief field notes. Time between interviews ranged from 1 to 4 weeks and follow-up interview questions were based on participants' responses, aimed at gaining clarification or more depth. 
After each interview was transcribed, researchers sent the transcription via email to the participant. As part of the member check process, participants were requested to review the transcript for accuracy and add any additional necessary information. Participants were informed about the limits of confidentiality related to using email and sharing files via Skype ${ }^{\mathrm{TM}}$ (e.g., hackers having the potential to access their data). Peer checks were also conducted by eliciting feedback from a colleague of the primary researcher, who had successfully completed multiple qualitative methodology classes, with regard to the transcripts, photos, and themes. The colleague examined the transcripts and developed his own themes, comparing them to the themes identified by the primary researcher. Themes were compared and organizational changes were made as a result.

\begin{abstract}
ANALYSIS
Data analyses followed the Stevick-Colaizzi-Keen method by Moustakas (1994), in which analysis occurs in several phases over the course of the study. The first phase includes identifying relevant personal experiences of the primary researcher, which Moustakas refers to as bracketing. Researchers chose to use the concept of bridling, rather than bracketing. Bridling acknowledges that it is impossible to truly set aside one's biases, but during our research process, we can "slacken" our beliefs in order to allow more room for new understandings and meanings to emerge from the phenomena being studied (Dahlberg, 2006). Moustakas method also asserts that the first phase includes data collection. The second phase is a content analysis, and the final stage is thematic. During the final stage, a holistic description of the phenomenon was written, incorporating composite textural and structural descriptions, capturing the essence of shared experience. The rigor of the study was strengthened through establishing credibility, transferability, dependability, and confirmability, which included using multiple forms of data, member checks, and peer check.
\end{abstract}

\title{
RESULTS
}

Participants' narratives were rich in description and provided meaningful data that allowed the following themes to emerge: (a) diverse processes of building a multiple nationality identity (e.g., through immigration, upbringing, etc.); (b) intentionality about identifying with multiple nationalities; (c) reactions of others; (d) cultural intelligence-openness, appreciation, and acceptance of diversity; (e) similarities between cultures, language, religions, and spiritualties across nationalities; (g) feeling connected or disconnected through language; (h) where is home, and do I belong?; (i) professional identities; and (j) importance of food. Participants' narratives were shared with a consideration of how their identification with multiple nationalities intersected with other identity areas.

It is important to note that all themes were approached from an intersectionality framework, with the purpose of gaining a richer understanding of how people make sense of the various identities they belong to. Intersectionality aims to conceptualize the whole person and strive to understand how the person makes sense of her-/himself. Participants' lived experiences encapsulated other salient identities in addition to their nationalities (e.g., influence of gender, religion and spirituality. Most often, research has focused on the interacting effects of gender, race, ethnicity, class, disability, sexual orientation, national origin, and religion/belief system (Cole, Piercy, Wolfe, \& West, 2014; Hancock, 2007; Maciel \& Knudson-Martin, 2014; Oleksy, 2011).

Some of these salient identity layers may not have emerged in this study due to not being prominent for participants, such as identifying with the majority in regards to sexual 
orientation, being able bodied, and having political access. Surprisingly, gender was not discussed in depth or brought up as being important when considering the intersectionality of gender and nationality, even when prompted. Even if some of the expected intersecting areas did not emerge in as much depth or at all, participants did discuss other identities they found important in conjunction to their multiple nationalities not typical in the intersectionality literature, such as their professional identities. The way participant's viewed themselves in their professional lives was a commonality amongst individuals. Intersecting identity is important to consider, especially for psychologists and mental health professionals, as it can assist in the lifelong striving towards multicultural competence and social justice. Intersectionality researchers strive to provide data to support positive social change and make an attempt to understand participants from their worldviews (Shields, 2008; Walker, 2003). Thus, even though the intersectionality of individuals was not fully captured, as expected, some of the salient identities of participants emerged and were explored in their stories through an intersectionality lens.

\section{Process of constructing a multiple nationality identity}

An essential aspect of understanding participant's narrative was their experience of coming to identify with multiple nationalities. For some participants, it was through migration; for others, it was their familial upbringing; and for some, it was a combination. Furthermore, relationships, familial or romantic, served as an important source of support in maintaining the multiple nationalities. Lastly, documentation and legal status for several participants served as a catalyst to pursue multiple nationalities. The ways in which participants came to identify with their multiple nationalities is consistent with research, which notes that it is not uncommon for individuals to internalize more than one nationality, either through living in a multicultural community or cross-cultural marriages, or through internalization of multiple nationalities through immigration (Benet-Martínez \& Haritatos, 2005). 2010).

\section{Migration}

For some participants, moving to a new country opened the doors to identifying with multiple nationalities. This migration occurred as a child, such as for Nina who moved to the Netherlands at age 8, and for Mari, to the U.S. as a baby. For others, it was a choice they made as an adult such as for employment opportunities, as was the case for Shanti, who moved to Argentina from Mexico, or Michael who moved to Germany. Some participants migrated to a nationality with which they had already started to identify due to their parents being of that nationality, such as Derek (moving to the U.S. during high school), Steve (moving to the U.S. for his undergraduate studies), and Elinor (moving to Israel after having visited several times).

\section{Relationships}

Mari, Steve, Taina, Suhaili, Derek, Maria, and Maria were exposed to their multiple nationalities via their parents. In their cases, their parents came from differing national backgrounds, such as Mari whose father was from Japan and whose mother originated from Finland. While Michael was introduced through his parents to the Catalán and Spanish nationality, it was through his career pursuits and migration that he came to also identify as German. Shanti, unlike others, had parents of a similar national background-Mexican.

Participants were also influenced by other relationships, such as romantic partners, to new nationalities or ways to foster their current national identities. This was the case for Suhaili who was influenced by her fiancée's multiple nationalities. A shared Spanish nationality with her partner allowed her to deepen her connection to this nationality. Elinor, like Suhaili, was 
also influenced by her fiancée, who is Australian. Both Elinor and her fiancée have a shared Jewish identity. Common ground within the Jewish community, as well as attending similar Jewish camps, allowed them to share similar ways of identifying with the Israeli nationality. For Michael, having his wife also identify as Spanish and Catalán encouraged him to explore these nationalities, while also recognizing the added complexity of his German nationality. Steve and Derek shared that their romantic partners have also encouraged them in exploring their multiple nationalities.

\section{Importance of documentation and legal status within a nationality.}

Participants recognized that receiving documentation and legal status for the respective nationality was a catalyst in identifying with multiple nationalities. Derek, Maria, and Nina expressed that receiving their social security card, passport and name change, respectively, was instrumental in their process of identifying with multiple nationalities. Derek shared that receiving his social security card indicating, he was a resident, allowed his identity as American and Canadian truly "sink in." Maria echoed this sentiment, explaining that receiving the Chilean passport encouraged her to start learning about Chile and make plans to move there.

For Nina, it was the documentation that her name change was official; having a Dutch name meant that she truly fit in as a Dutch person and was more meaningful than having Dutch citizenship.

This document made it actually finally official. So this was an important moment of when I could actually say, "Now I'm really Dutch, and I don't have my Russian last name anymore, so now I'm a truly Dutch person so to say." I think actually that document represents quite well, like, the transition I went through, at least the first stage when I first tried to get rid of the Russian nationality and try to assume as much as I could my Dutch nationality.

Just as documentation was helpful for participants in becoming aware of their multiple nationalities, the lack of it was identified as weakening the relationship. This was the case for Steve, who does not have a Japanese passport, instilling the sense of being gaijin (foreigner).

\section{Intentionality about identifying with multiple nationalities}

All participants were intentional about choosing to recognize their multiple nationalities. For some it was a process of purposefully learning about their nationality or recognizing how strongly they related/connected to their multiple nationalities over time. Furthermore, for those participants who were introduced to their nationalities through family, they made a conscious choice to continue to identify with these nationalities into adulthood. For example, Suhaili expressed:

I'm old enough ... when I was a kid, I couldn't choose if I want to go with my parents to vacation or not. And when I was living at home, I was more or less obligated to speak my parents' languages, this is not something you can choose. When you are 18 or 20, you leave your home because you go for studying, you can choose your own life, you can say "okay, this is my past, this is my family, and I love my family, but I would like to go another way." I never made this question for myself because I always felt good being the way I am and having the past I have.

\section{Changing levels of connectedness to different multiple nationalities.}

Participants experienced shifts over time with regards to how strongly they connected to their nationalities related to developmental changes, exposure to the nationalities, where they were 
residing, or ability to travel. Common to the process of identifying with multiple nationalities was a shared experience of making an intentional choice, despite varying levels of connectedness to national identity, to maintain their identification with multiple nationalities. For example, as a young child, Mari identified primarily with her Japanese and Finnish nationalities. As she became older, her American identity became stronger, and her Japanese identity faded to a point where she thought it was nonexistent.

Similar to Mari, Derek also noticed a shift in how strongly he identified as Canadian and American. Derek's story related to Mari's, as his sense of national identity has shifted over the years to a point that he at times wonders if his Canadian nationality is still present. Steve's sense of identifying as Japanese and American has shifted over the years. Early on, these identities were equal and now his American nationality has become stronger with the experiences he creates in the U.S. Elinor's identity shifts as she travels, sometimes identifying as American and other times more strongly as Israeli. Michael reflected that his sense of national identification has changed, and he feels positive that it will continue to evolve as he gathers more life experiences. Suhaili expressed that, because she grew up with all three nationalities, she feels confident she will always identify with all three, yet she has recognized that some of identities are stronger than others.

Though participants discussed varying degrees of connectedness with their nationalities, they also discussed the process of re-integration of identities. Reflecting, Nina discussed how as a child, she actively tried to make her Russian nationality nonexistent: "I was trying to make it [Dutch identity] a 100\%." Wanting to fit in, Nina felt that her Russian side needed to be extinguished, to the point that Nina demanded that her mother not speak to her in Russian. Maria stated she would not have participated in the current study 10 years previous because although she had learned about her Chilean roots, at that time, she solely considered herself to be Russian. She expressed that her identification will most likely be different again in 10 years, evolving and constantly changing.

\section{Intentionality of learning about and being involved with multiple nationalities.}

Some participants discussed how they purposefully took time to learn about the nationalities that they were less familiar with in order to strengthen their connection with the nationality. For example, Maria spoke about how important it is for her to learn about the history of Chile and speak Spanish in order to feel that she has the right to identify as Chilean. "I think there are some points that you have to respect, you have to know the history . . . for me it's disrespectful to kind of say that you are from that nationality . . . and not knowing the history or the language of that place or something like that."

Elinor's work experience at a place where she was the only American, "helped me solidify and understand my relationship as an American." Furthermore, traveling back to the U.S. to visit family and friends, in addition to visiting her boyfriend's family in Australia, all help her evaluate and assess her different national identities and make an intentional choice to identify as American and Israeli. Michael discussed how his exposure as a child to the Catalonian and Spanish culture helped define his identification with multiple nationalities. Mari shared her journey deciding whether to identify as Japanese. Due to her father being Japanese, and her physical appearance matching the nationality, she actively explored the culture in high school and made the choice that she did not want to identify as Japanese. "I stopped trying to be Asian because there is no point of trying to be something you don't feel strongly about." However, as time has passed, Mari feels less pressured by others and she is now reconsidering her 
identification with multiple nationalities-“Actually I'm re-exploring my Japanese heritage a little bit."

\section{Reactions of Others}

Participants explored how others' reactions to them had an impact on how they made sense of their multiple nationalities. They described a range of reaction from others when finding out that participants came from a background of multiple nationalities. Reactions of others were based on the participant's accent, physical appearance, and name and seemed to vary culturally.

For Steve, it made it harder to identify as Japanese because in Japan, he is labeled as gaijin. Steve explained that in Japanese culture one is either Japanese or gaijin. Steve described that foreigners are seen as "big, blundering, and boisterous ... And I kind of see myself like that from my Japanese side." Yet when Steve thinks about himself in the context of his American nationality, this description does not fit. Mari noted that her family considers her Japanese, but others in Japan do not. In the U.S., she is often identified as Japanese, but not Finnish. The experience of Mari highlighted that in the context of the U.S., people tend to notice and emphasize non-European identities, such as Latino American or Asian America.

Taina described a similar experience, in which other individuals label her as Hispanic, but not American or Japanese. Suhaili's experience aligns with others, "It doesn't matter what I do or what I say, most of the people always say the 'Spanish girl' to me." Nina agreed with others, expressing it was other people at times that made it challenging to identify with more than one nationality, especially when she is told from people in Russia. She described being told, "Oh you're so Dutch, you're not Russian at all, come on." Elinor's identification as American and Israeli can at times be challenging due to context. In particular, she faces difficulties in Israel of not being accepted as Israel, which has led Elinor to with the Israeli nationality in a unique way.

In the Israeli culture in and of itself, is very exclusive versus I would almost say the American culture is very inclusive, not as individuals, but as groups, right. ... So, that cultural reaction from the other people has made it very difficult for me to feel I'm Israeli, when everyone is telling me suddenly you're not, suddenly I'm not Israeli.

For Derek, he noticed an internal pressure as a result of reactions by others that he perceived or thought he perceived. "I probably would be identified by my friends and family as: 'oh you are living in the US now' and they would identify me as someone who left Canada and is American now." The invalidation participants received from others added further complexity to participants making sense of their multiple nationalities.

\section{Cultural Intelligence-openness, appreciation, and acceptance of diversity}

Participants also described the theme of cultural intelligence, or openness, appreciation, and acceptance of diversity, and how cultural intelligence strengthened their identity with multiple nationalities. All 10 participants expressed an appreciation of open mindedness, stemming from their experiences identifying with multiple nationalities. This notion involved having a raised awareness that there are other cultures in the world with different belief systems and customs, along with a stronger patience and tolerance to learn from other people. 
Participants addressed the idea of cultural intelligence-the ability to relate and work across cultures - in a variety of ways. Taina shared that identifying with more than one nationality has allowed her the opportunity to develop and establish "so much cultural intelligence and being able to go to different countries and communicate, understand that we come from different cultures and be accepting and appreciating of other cultures as well." Suhaili expressed similar thoughts in feeling more open and having a better understanding of the lives of other individuals from various backgrounds.

Many participants thought that being more open-minded also made it easier to communicate with individuals from all over the world and gave them a sense of being a "global citizen." As Mari expressed, "I never grew up with thinking that one world view is just correct and that this is the only way that things are." She spoke about realizing the vastness of the world and how "it's worth exploring these things and understanding where I come from, and get to know those cultures, and things like that." Shanti noted how being exposed to different cultures and identifying with multiple nationalities has helped her challenge her prejudices and assumptions.

So then, this is another thing I learned from when I was out of my country and my comfort zone, that I learned not to judge anyone by the way they look, it's about what they have in their brains and in their heart, and the difference there is how a culture, in this case, my own culture limited me on going outside of my comfort zone to learn and meet different people.

Michael agreed with being more open-minded, something he hopes to pass on to his family, and said, "You just keep yourself open to many options to have new experiences."

Elinor shared that she sees many advantages of identifying with more than one nationality and that it is a humbling experience.

Advantages is I feel much more worldly, and I also feel the process that took me to identify here and actually live here and get acclimated here is very humbling ... the tools that I have to solve problems and to think critically is much bigger toolbox, again because I have those two things to draw on.

Shanti agreed with Elinor, that identifying with more than one nationality has helped her evolve to have a more open and accepting worldview. Shanti, on numerous occasions expressed her recognition that we are all humans, and we can find similarities amongst differences: "I conclude that at the end, you can find people with very similar profile and background that you have. It's not about the country you live." Nina also expressed the importance of connecting with others and putting nationality second. The idea of becoming a global citizen and the importance of treating people fairly and equally seemed a strong value carried and expressed by many of the participants. Shanti, who has developed an ability to view new things with an open attitude, expressed, "The cultures are everywhere, but if you don't want to learn from them then they are going to be there forever and you are not going to grow inside."

Suhaili shared that she loves and appreciates all the countries she is from. She selects the parts that make sense to her and appeal to her, saying, "I pick a little bit of here and a little bit of there." Michael also expressed a similar thought process of taking what he believes are the most positive aspect of each nationality and then integrating them to make sense for himself. Picking and choosing, whether consciously or unconsciously, 
was very common throughout and expressed in one form or another by each participant.

\section{Similarities between cultures, languages, religions, and spiritualties across nationalities}

Participants discussed how overlapping cultures, languages, religion, spiritualty, and a general consistency across nationalities helped them build a stronger connection to their nationalities. Suhaili noted that all three nationalities she identifies with share a devotion to Catholicism. Two share a Mediterranean culture. Shanti also noted that shared Catholic bonds in both Mexico and Argentina made it easier for her to transition between the two. Additionally, shared language between the countries, despite notable differences, also eased the transition. Derek, too, discussed how cultural similarities between Canada and the U.S. made it easy for him to identify with both, but also made it difficult to differentiate. Elinor found the Jewish culture connected her to both nationalities-having a Jewish community in Israel and the U.S. I was thinking, like, more when my two identities started, how did they form and how did they, how did I become to have such a strong identity with Israel, and it's really through one of the strongest, not the only, one of the strongest ways is through my Jewish identity.... I knew that my Jewish connection is really central to both identities, like, it directly answers what you requested of me.

Alongside the idea of consistency between the various nationalities, participants also discussed their experience of developing internal consistency-feeling they could adapt and fit in with the various nationalities-while maintaining genuineness. Shanti created a process for herself to help her settle in to new places without losing the sense of who she is. Elinor explained it as being culturally adaptive, which may result in portraying herself differently, but not changing who she is or how she sees herself. This matched most of the participants' experiences including Michael, Taina, Suhaili, Derek, Nina, and Maria-perceiving themselves to be the same regardless of their multiple national identities, but adapting their actions or behaviors to the environment. In order to keep a consistent sense of self, Michael shared it was important to be able to integrate the various nationalities, in order to have all of them represented. Nina discussed her experience of trying to reintegrate the Russian nationality into her life, which became lost when she was actively trying to fit in as Dutch. She now is looking at balancing how she can integrate both and working towards becoming a global citizen.

\section{Feeling connected or disconnected through multiple languages}

Participants brought up the realm of communication, i.e., language, as a determining factor in whether they felt connected or disconnected to the nationalities. Being able to speak their nation's language or languages was an important component of participants' identity process.

\section{Feeling connected through language.}

Maria emphasized that, in her process of identifying as Chilean and Russian, it was vital for her to learn Spanish. Due to having less exposure to Chilean culture, learning the language was a key step for her to feel that she was allowed to call herself Chilean. Suhaili expressed that her Croatian nationality is less integral to her identity than her Spanish nationality because she feels her Spanish is more fluent then her Croatian and she feels she is more involved in Spanish activities. Michael described how his journey of learning German helped him feel connected and comfortable. He sees the importance of being multilingual and hopes to teach his children. Being able to communicate with others seems to invoke a sense of belonging, which appears important when a person identifies with a nationality 
Speaking fluent Finnish was an important reason that Mari felt very close to her Finnish nationality. It helped her be involved in the Finnish community both in the U.S. and during visits to Finland. Without speaking the language, Mari pondered whether she would have felt her Finnish identity so acutely. Along with others, Taina shared that her ability to communicate with people was important to her. In Japan, she communicates with the limited Japanese she knows and the help of her mother translating in order to connect with her Japanese family. Derek also noted that by identifying as Canadian and American, he found it easy to transition between the two as both nations share a common language-English. By not having an accent, he was less likely to be "pigeonholed" and could more easily blend in.

\section{Feeling disconnected through language.}

Some participants spoke of their realization that their ability or inability to speak certain languages negatively impacted their sense of connection. In order for Nina to reconnect to her Russian nationality, she began to study the language and culture. She described how realizing she could not speak with her family in Russia spurred her desire to reconnect with her origins. Being unable to speak the language paralleled her identifying less strongly with the Russian nationality. Elinor described how language helped her adapt, yet also was a reminder that she was not considered Israeli by other Israelis.

Even though I speak perfect Hebrew . . . the second they hear my accent, no matter how complicated a sentence I'm speaking, often they will switch to English, and whether they switch to English or not, that's a whole other story that we can talk about. They can already see I'm not Israeli; whereas in the States, there's no outside thing to define I'm not American.

Shanti had a similar experience to Elinor. Despite speaking fluent Spanish, this was still, at times, a barrier when she lived in Argentina. "Although we speak Spanish in Mexico and Argentina, we have different meanings of certain words that, for me, could be a nice word, but for them, the worst word in the world." She further encountered language difficulties while living in Puerto Rico as the Spanish there that she described has been heavily mixed with English. Thus, despite being fluent in the language of each nation in which Shanti has resided, she still encountered communication difficulties that were related to the actual language as well as the cultural way of communicating.

Taina also discussed how, despite being fluent in Spanish, she reported being more selfconscious in Puerto Rico, because she feels awkward when she cannot understand the other person or has to ask them to slow down. Higher expectations of herself, complicated by the fact that she feels she "looks Hispanic," result in her feeling more self-conscious:

They expect that I'm following the conversation, because, you know, I look Hispanic. So they expect me to be able to speak it and understand it, but I'm very embarrassed, because I have to tell them, "I'm so sorry, can you repeat that?" or "Can you speak slower?" or something. That's what I get embarrassed about.

Mari echoed other participants' experiences bringing up that not being able to speak Japanese led to a barrier in communication, and despite feeling close to her Japanese family, it made it more difficult. The mastery of a language, or failure to gain mastery, had a strong impact on participants' identification with a nation. Being able to communicate with others and not being easily differentiated from others based on language has had a powerful influence of feeling like they belong. 


\section{Where is Home, and Do I Belong?}

Participants expressed feeling that there are many benefits in identifying with multiple nationalities, however, one salient drawback seems to be not knowing where home, is or whether they belong in the nation in which they reside. Alongside being unsure of where to call 'home,' participants described how they often found themselves being separated from their families. Steve shared, "I guess the only disadvantage I would say is that my family isn't here. So having that real sense of belonging you know somewhere, it's not something I really have." Michael also shared his internal debate about not knowing where the best place would be for his family to live, balancing where he feels comfortable in comparison to his wife and children, "where is the right place? Where do you imagine your life? It is the only drawback." Fortunately, Michael shared that there is not much difficulty traveling back and forth between Spain and Germany, "In terms of the Spanish and Germans, with the EU, it makes it very easy, changing from one place to another."

Elinor's experience matches that of Steve and Michael, sharing, "I think it makes it harder for me, because I don't feel at home ... I don't really identify with the general public in either places. ... I also feel like I'm always going to be in the scenario of the grass is greener, because I know both lawns sort of thing so that's also very frustrating." Elinor further highlights her struggle, wondering "if I only knew one thing, maybe I wouldn't be so torn between the two?" Conversing with others who have lived in different places resulted in Elinor hearing a common message of "feeling that you don't belong here nor there, like I feel now, I'm stuck." Steve expressed that identifying with both nationalities and having lived in both countries has led to him feeling like a foreigner-in Japan due to being labeled as gaijin and in the U.S. because:

I don't know the same TV shows the kids grew up with, if anyone talks about anything that was going on in the west, you know, during the kind of my younger years, I kind of have the Japanese version of that, you know, so TV shows, music, pop culture, so I guess in that regards, it always made me feel that I'm newer here, too.

Taina expressed that the disadvantages she notices and struggles with seem to feel "more on a psychological" level in the sense that she feels she can't really belong. She also wonders how others perceive her, and whether they believe that "she's not truly Japanese because she's only half."

Mari expressed similar confusion of not being sure whether she belongs. She highlighted that this was very salient during her high school years when she was constantly figuring out the idea of "where do I belong?" Nina expressed that it was other people, who, at time, made it challenging to feel like she belongs, especially when she is told from people in Russia, "oh, you're so Dutch, you're not Russian at all, come on." Nina described this sense that maybe neither country accepts her fully. Participants shared this general uncertainty of where their home is and their ambivalence about whether they belong and agreed that this confusion was a challenge related to identifying with multiple nationalities.

\section{Professional identities}

As participants discussed making sense of their multiple national identities, they also brought up the importance of their professional identity. Participants' professional lives contributed to strengthening or fostering their multiple nationalities. As Michael expressed, it was his career that triggered the process of moving to Germany and identifying as German. Nina, on the other hand, identifies as a global citizen and has thus aligned her professional interests. She works to 
alleviate problems from a thematic global perspective, addressing concerns in multiple countries.

Derek was in agreement with Michael and Nina in that his professional identity was very salient. Derek is an entrepreneur who has started his own business with a close friend. Establishing his business in the U.S. has helped Derek form a more positive view of what it means to be an American and has played a key role in identifying more strongly with his American nationality, "Yes, I have this opportunity, and America is helping me do this thing." As Derek continues to establish himself in the U.S., he has noticed that his American nationality is growing and his Canadian sense of self is growing more diminutive. Thus, his professional life helps him feel closer to his American nationality and further away from his Canadian nationality

Maria's professional identity was also very salient, and her area of interest in her research allows her to learn more about Chile while staying connected to Russia. Maria spoke that the experiences she has created have been instrumental in her process of making sense of herself. "I have had very different experiences and variety of experiences, work and studies," shaping her identity. Elinor presented a book made by colleagues and described how her professional identity and work experience has influenced her identification process. The book reminds her of working primarily with American students on a staff that was Israeli. Her work experience often evoked the sentiment "I'm American and I'm Israeli." For students, she was a role model because she spoke Hebrew, was on an Israeli team, and was successfully living in Israel, something for which many of the students strived. Interestingly, while students saw her as an American who successfully integrated, the staff saw her as Israeli. Through her career, she realized, "I got to be in both worlds simultaneously" encouraging her to explore her sense of nationality.

\section{Importance of Food}

Even though not all participants discussed food, four participants brought up the exposure to food as an important component in helping them identify with more than one nationality, such as Taina learning how to prepare Japanese cuisine by watching her grandmother or Mari eating Japanese cuisine growing up. Through a memento he brought, Steve shared how food was an indicator that he identifies with more than one nationality. The picture shared was of delicious Japanese food item he buys at a store selling Japanese products. "I think probably the biggest difference between what you see between something that I do, versus what a normal American would do or someone who grew up here, is probably food." Food brought comfort and seemed to indicate a piece of stability. As Steve shared, regardless of where he lives, he always makes the effort of finding Japanese to prepare. Suhaili also emphasized the importance of food as shown in her memento depicting Croatia. The spices included in the picture are common to Croatian cooking. The picture features a green spice called Vegeta, similar to a vegetable broth, and a red paste called Ajvar, used like ketchup. Several times she referenced that her cooking reflects her exposure and immersion with the cultures she grew up in. Cooking foods that might not be found in Germany is one way others can identify that she is influenced by other nationalities. Participants felt connected to each of their nationalities through cuisine.

\section{RECOMMENDATIONS FOR MENTAL HEALTH PROFESSIONALS AND PSYCHOLOGISTS}

One purpose of the present study was to obtain recommendations for mental health professionals and psychologists when working with individuals who identify with multiple 
nationalities. Each participant was asked to make recommendations for mental health professionals based on this premise. Insights, either through personal experience or through people they knew, were shared.

A consistent response from participants when considering what they would see as important when receiving mental health services was for the clinician to have basic knowledge of the nationalities with which they identified in order to gain a contextual perspective. Most importantly, participants expressed wanting and open-minded clinician. The clinician did not need to identify with the same nationality, or even identify with multiple nationalities, but should be aware that other worldviews exist. An openness and curiosity about other cultures is something that could help improve therapeutic relationships by allowing clinicians to learn from their clients. This is consistent with the literature exploring cultural competence, which highlights the importance of the therapist taking an open, receptive, and respectfully curious stance (Cole et al., 2014). Elinor, in particular, noted that having a clinician work within the context and framework of her multiple nationalities was instrumental and powerful in her journey of making sense of her nationalities. Suhaili shared an experience of a close friend who felt misunderstood by the clinician in terms of her national background. Thus, the importance of continually striving to be culturally competent psychologists and mental health clinicians is further reinforced as a necessary precursor to helping clients from multiple nationalities feel understood.

An area of strength for participants is their embodiment of cultural intelligence, which emerged for participants through their exposure and identification with multiple nationalities. This area of strength could be beneficial to highlight in counseling, especially when the client is facing distress. It is important to address not only the strengths, but also difficulties experienced by this population. One area that was identified as more challenging was reactions of others based on their physical appearances, accents, names, etc. Participants were often labeled by others, based on discriminating characteristics like language or physical appearance, that were not accurate or encompassing of their layered identities and caused feelings of exclusion. Furthermore, mislabeling or ignoring other important identities may lead to identity confusion, an important area for clinicians to explore. This theme also highlights the importance of addressing and discussing cultural differences in the counseling room.

An important consideration that Taina brought to the forefront was for clinicians to be aware of language and discuss how this will impact treatment. She noted that for herself, language may not be as crucial, especially if she sought services in English; but, she was aware of the challenge that exists for those receiving treatment not in their first or main language. Language is indeed very important and, as various studies reflect, narratives expressed in the language in which the event occurred tend to be more elaborate and richer in detail. (SoftasNall, Cardona, \& Barritt, 2015). Research also suggests that in the U.S., those less proficient in English are less likely to seek mental health services (Bauer, Chen, \& Alegría, 2010). Findings seem to indicate an interaction between language and other cultural factors that can create a barrier to seeking mental health services. Exploring the impact of language with clients who identify with multiple nationalities may be impactful and beneficial. It is also important to be self-aware as a clinician of how language is being utilized in the room as some research has found that "counselors frequently impose their language style and preferred dynamic onto their clients" (Torres-Rivera, et al., 2008, p. 11). It is also essential for mental health clinicians to be aware of the power differential that may result from working in the clinician's primary language (Ali, 2004; Softas-Nall et al., 2015). 
Participants identified various avenues toward their journeys of identifying with multiple nationalities, migration being one of them. Migration is an integral part for a significant portion of the human population and is growing for diverse reasons and means with varying social effects (Amrith, 2014). An important point to note for clinicians is that, as migration continues to increase, they are more likely to encounter clients impacted by struggle of reconciling a desire to 'fit in' while maintaining their previous nationality. This was the case for Nina who expressed this conflict of wanting feel she belonged, but not understanding that she could not only adapt, but also maintain her Russian nationality. Failing to understand this alternative led her to actively try to rid herself of her Russian nationality, which resulted in distress as she grew older. Providing support to the client in finding a balance between integrating aspects of the new culture in order to fit in comfortably while keeping important parts of the heritage culture is an important focus area.

Participants each spoke a great deal about yearning to feel a sense of belongingness. The questions, "Where is home, and do I belong?" tap into Maslow's need for humans to belong. Thus, failure to feel belongingness could interfere with a person's capacity to self-actualize (Maslow, 1987). A research study by Taormina and Gao (2013) created several scales that explored Maslow's hierarchy of needs and determined which were met and how they impacted each other in a sample of Chinese individuals. From this study, the need for belongingness was influential to achieve higher needs, such as self-actualization. According to the study, family emotional support was an important component for belongingness. Feeling a lack of home and belongingness can impact a person's overall psychological well -being; therefore, it may be important for clinicians to assess social support and other factors important in facilitating one's sense of well-being. A clinician's ability to recognize this dilemma, which may last a lifetime, and validating it, can be crucial in the individual's process of making sense of themselves and their environment.

Furthermore, participants highlighted the importance of their professional identities. Pursuits of career aspirations, at times, introduced participants to new nationalities or helped them make sense of their nationalities. For example, establishing his business in the U.S. has helped Derek form a more positive view of what it means to be an American and has helped him identify more strongly with his American nationality. Considering the importance of client's professional identities when providing counseling services is an important area to explore, as professional identities can serve as a protective factor and area of strength. Professional identity and professionalism relates to a person's identity development as a whole (Trede, Macklin, \& Bridges, 2012). Wilson et al. (2013) define professional identity as: "the integration of personal values, morals, and attributes with the norms of the profession." Participants discussed their professional identity in how it strengthened their connections to their nationalities. Professional identity impacts personal identity development due to the individual integrating the knowledge, skills, and values with one's own unique identity and core values (Thistlethwaite, 2014; Boisaubin et al., 2014).

Participants in this study intentionally identified with multiple nationalities. Factors that contributed to maintaining and adopting new nationalities is an important area to consider, especially as some chose to not integrate a nationality. This was an area that was not explored in as much depth in the current study, but would be beneficial to do in future research and determine the impact it has on mental health. 
These implications provide not only considerations for mental health professionals, but also opportunities for future research. The findings of this study may provide information in the area of multicultural competencies of psychologists and mental health professionals. In particular, this study provided a vantage into the lives of individuals identifying with multiple nationalities and allowed a glimpse into the process of making sense of their multi-layered identities. Information learned may be beneficial in applied psychological practice and can be integrated into treatment interventions and goals.

\section{LIMITATIONS AND CONCLUSION}

Overall, this study attempts to foster international connections among psychologists by engaging in multicultural research on an international level. An area for future research would be to compare individuals who intentionally decided to maintain their multiple nationalities with those who do not, to better understand how individuals actively construct their identities. Additionally, longitudinal studies, both quantitative and qualitative in nature, would also add a more thorough understanding of the experiences by better capturing the various dynamics that impact the varying levels of connectedness each nationality. Another interesting avenue for research was presented through participants' discussion of what mental health professionals and psychologists can do to foster effective treatment for individuals who identify with multiple nationalities. Participants highlighted the importance of the clinician being open and understanding of other cultures. It will be essential to explore how clinicians can develop this open and non-judgmental stance. Future research could also explore whether allowing participants to be interviewed in their primary language may add richness to the narratives of participants, as all interviews in the current study were conducted in English.

As psychologists and mental health professionals become more knowledgeable about diversity and multiculturalism, they will likely also develop cultural competencies. Results can hopefully sever to inform discussions for future research and clinical practice. Increasing our understanding of the lived experiences of individuals belonging to multiple nationalities will help us continue to develop cultural competency and foster a safe space for our clients. Better understanding the various dynamics at play when making sense of multiple nationalities will guide clinicians in taking a more global perspective in our clinical work. As Mari noted, "I never grew up thinking that one worldview is just correct and that this is the only way that things are," which is poignant and important message for clinicians as well. 


\begin{tabular}{|c|c|c|c|c|c|c|}
\hline & & & $\begin{array}{r}\text { APPEN } \\
\text { Table } \\
\text { Participant D }\end{array}$ & $\begin{array}{l}\text { IX } 1 \\
1 \\
\text { scriptions }\end{array}$ & & \\
\hline $\begin{array}{c}\text { Name } \\
\text { (Pseudonym) }\end{array}$ & Age & Gender & Nationality & $\begin{array}{l}\text { Country of } \\
\text { Residence }\end{array}$ & Language(s) & $\begin{array}{c}\text { Parents' } \\
\text { Nationality }\end{array}$ \\
\hline Mari & 26 & Female & $\begin{array}{l}\text { Finnish, } \\
\text { American, } \\
\text { Japanese }\end{array}$ & U.S.A. & $\begin{array}{l}\text { English, } \\
\text { Finnish }\end{array}$ & $\begin{array}{l}\text { Mother: } \\
\text { Finnish } \\
\text { Father: } \\
\text { Japanese }\end{array}$ \\
\hline Steve & 32 & Male & $\begin{array}{l}\text { American, } \\
\text { Japanese }\end{array}$ & U.S.A. & $\begin{array}{l}\text { English, } \\
\text { Japanese }\end{array}$ & $\begin{array}{l}\text { Mother: } \\
\text { Japanese } \\
\text { Father: } \\
\text { American }\end{array}$ \\
\hline Michael & 32 & Male & $\begin{array}{l}\text { Catalonian, } \\
\text { German, } \\
\text { Spanish }\end{array}$ & Germany & $\begin{array}{l}\text { Spanish, } \\
\text { Catalán, } \\
\text { German, } \\
\text { English }\end{array}$ & $\begin{array}{l}\text { Mother and } \\
\text { Father: } \\
\text { Spanish }\end{array}$ \\
\hline Taina & 24 & Female & $\begin{array}{l}\text { Puerto Rican, } \\
\text { Japanese }\end{array}$ & U.S.A. & $\begin{array}{l}\text { English, } \\
\text { Spanish, some } \\
\text { Japanese }\end{array}$ & $\begin{array}{l}\text { Mother: } \\
\text { Japanese } \\
\text { Father: } \\
\text { Puerto } \\
\text { Rican }\end{array}$ \\
\hline Suhaili & 35 & Female & $\begin{array}{l}\text { Spanish, } \\
\text { Croatian, } \\
\text { German }\end{array}$ & Germany & $\begin{array}{l}\text { German, } \\
\text { Spanish, } \\
\text { Croatian, } \\
\text { English }\end{array}$ & $\begin{array}{l}\text { Mother: } \\
\text { Croatian } \\
\text { Father: } \\
\text { Spanish }\end{array}$ \\
\hline Shanti & 46 & Female & $\begin{array}{l}\text { Mexican, } \\
\text { Argentinian }\end{array}$ & U.S.A. & $\begin{array}{l}\text { Spanish, } \\
\text { English }\end{array}$ & $\begin{array}{l}\text { Mother and } \\
\text { Father: } \\
\text { Mexican }\end{array}$ \\
\hline Derek & 26 & Male & $\begin{array}{l}\text { American, } \\
\text { Canadian }\end{array}$ & U.S.A. & English & $\begin{array}{l}\text { Mother: } \\
\text { American } \\
\text { Father: } \\
\text { Canadian }\end{array}$ \\
\hline Nina & 26 & Female & $\begin{array}{l}\text { Dutch, } \\
\text { Russian }\end{array}$ & Hungary & $\begin{array}{l}\text { Russian, Dutch, } \\
\text { English }\end{array}$ & $\begin{array}{l}\text { Mother and } \\
\text { Father: } \\
\text { Russian }\end{array}$ \\
\hline Maria & 26 & Female & $\begin{array}{l}\text { Russian, } \\
\text { Chilean }\end{array}$ & Hungary & $\begin{array}{l}\text { Russian, } \\
\text { Spanish, } \\
\text { English }\end{array}$ & $\begin{array}{l}\text { Mother: } \\
\text { Russian } \\
\text { Father: } \\
\text { Russian } \\
\text { and } \\
\text { Chilean }\end{array}$ \\
\hline Elinor & 28 & Female & $\begin{array}{l}\text { American, } \\
\text { Israeli }\end{array}$ & Israel & $\begin{array}{l}\text { English, } \\
\text { Hebrew }\end{array}$ & $\begin{array}{l}\text { Mother and } \\
\text { Father: } \\
\text { American } \\
\text { and } \\
\text { Israeli }\end{array}$ \\
\hline
\end{tabular}




\section{APPENDIX 2 \\ PROPOSED INTERVIEW GUIDE}

1. Tell me about your story of coming to identify with more than one nationality?

2. Would you say you have a sense of belonging to both nationalities or more to one than the other?

a. How has that happened for you?

b. How come this has happened for you?

c. How do you believe this has impacted you?

d. How would you describe the advantages or disadvantages are?

3. Apart from you belonging to more than one nationality, what other parts of you are important to you? (Clarification: Some people talk about their gender, ethnicity, or a variety of things; people talk about different things, what would be meaningful for you?)

4. Do you experience yourself differently and/or similarly in each of your nationalities and the way you see yourself?

a. How so?

b. What about that is meaningful for you and your life?

5. Tell me a little bit about your experience of putting together the different ways you are experiencing yourself?

6. I wonder what has helped you in trying to understand yourself? (Clarification: For some, other individuals could have been important or your sense of spirituality.)

7. I wonder if you have encountered obstacles or things that make it more difficult for you to identify with more than one nationality?

8. What else would you like me to know about living in more than one nationality that we haven't talked about?

9. As you know, I am studying to become a counseling psychologist, so if someone like you, belonging to more than one nationality seeks services with a professional like me, what is something you would like them to know to make them more helpful?

\section{References}

Ali, R. (2004). Bilingualism and systemic psychotherapy: Some formulations and explorations. Journal of Family Therapy, 26, 340-357. doi: 10.1111/j.1467-6427.2004.00288.x

Amrith, S. S. (2014). Currents of global migration. Development and Change, 45, 1134-1154. doi: $10.1111 /$ dech.12109

Bauer, A. M., Chen, C., \& Alegría, M. (2010). English language proficiency and mental health service use among Latino and Asian Americans with mental disorders. Medical Care, 48, 1097-1104. doi:10.1097/MLR.0b013e3181f80749

Benet-Martínez, V., \& Haritatos, J. (2005). Bicultural identity integration (BII): Components and psychosocial antecedents. Journal of Personality, 73, 1015-1047. doi:10.1111/j.1467-6494.2005.00337.x

Boisaubin, E. V., Clark, M. A., Mihalic, A. P., Sadler, J. Z., Sapire, K. J., Spike, J. P., ... \& Dalrymple, J. L. (2015). Professional Identity Formation: Creating a Longitudinal Framework Through TIME (Transformation in Medical Education). Academic Medicine, 90, 1-7. doi: 10.1097/ACM.0000000000000719

Casas, J. M., Park, Y. S. \& Cho, B. (2010). The multicultural and internationalization counseling psychology movement: When all is said and done, it's all multicultural, isn't it? In J. G. Ponterotto, J. M. Casas, L.A. Suzuki, \& C. M. Alexander (Eds.), Handbook of multicultural counseling (pp. 189-200). Thousand Oaks, CA: Sage.

Cole, E. M., Piercy, F., Wolfe, E., \& West, J. M. (2014). Development of the multicultural therapy competency inventory-client version. Contemporary Family Therapy, 36, 462-273. doi: 10.1007/s10591-014-9320-8

Creswell, J. W. (2007). Qualitative inquiry and research design: Choosing among five approaches (2nd ed.). Thousand Oaks, CA: Sage. 
Dahlberg, K. (2006). The essence of essences-The search for meaning structures in phenomenological analysis of lifeworld phenomena. International Journal of Qualitative Studies on Health and Well-Being, 1, 11-19. doi:10.1080/17482620500478405

Hadley, E. J. (2004). National identity. In J. Dewald (Ed.), Europe,1450 to 1789: Encyclopedia of the early modern world (pp. 243-246). New York, NY: Gale Virtual Reference Library.

Hancock, A. (2007). When multiplication doesn't equal quick addition: Examining intersectionality as a research paradigm. Perspectives on Politics, 5, 63-79. doi:10.1017/S1537592707070065

Hanna, P. (2012). Using internet technologies (such as Skype) as a research medium: A research note. Qualitative Research, 12, 239-242. doi:10.1177/1468794111426607

Erikson, E. H. (1950). Childhood and society. New York: Norton.

Johnson, J. C., \& Weller, S. C. (2002). Elicitation techniques for interviewing. In J. F. Gubrium \& J. A. Holstein (Eds.), Handbook of interview research: Context \& method (pp. 491-514). Thousand Oaks, CA: Sage.

Maciel, J. A. \& Knudson-Martin, C. (2014). Don't end up in the fields: Identity construction among Mexican adolescent immigrants, their parents, and sociocontextual processes. Journal of Marital and Family Therapy, 38, 484-497. doi: 10.1111/jmft.12044

Marcia, J. E. (1987). Identity in adolescence. In J. Adelson (Ed.), Handbook of adolescent psychology. New York: Wiley.

Masella, P. (2013). National identity and ethnic diversity, Journal of Population Economics, 26, 437-454. doi:10.1007/s00148-011-0398-0

Maslow, A. H. (1987). Motivation and personality (3rd ed.). Boston, MA: Addison-Wesley.

McGoldrick, M., Giordano, J., \& Garcia-Preto, N. (2005). Overview: Ethnicity and family therapy. (3rd ed.). New York, NY: Guilford Press.

Moustakas, C. E. (1994). Phenomenological research methods. Thousand Oaks, CA: Sage.

Oleksy, E. H. (2011). Intersectionality at the cross-roads, Women's Studies International Forum, 34, $263-270$. doi:10.1016/j.wsif.2011.02.002

Platt, J. J., \& Laszloffy, T. A. (2013). Critical patriotism: Incorporating nationality into MFT education and training. Journal of Marital and Family Therapy, 39: 441-456. doi: 10.1111/j.1752-0606.2012.00325.x

Polkinghorne, D. E. (2005). Language and meaning: Data collection in qualitative research. Journal of Counseling Psychology, 52, 137-145.

Shields, S. A. (2008). Gender: An intersectionality perspective. Sex Roles, 59, 301-311. doi: 10.1007/s11199-0089501-8

Softas-Nall, L., Cardona, B., \& Barritt, J. (2015). Challenges and diversity issues working with multilingual and bilingual couples and families: Implications for counseling. The Family Journal: Counseling and Therapy for Couples and Families. 1-5. doi: 10.1177/1066480714548402

Taormina, R. J., \& Gao, J. H. (2013). Maslow and the motivation hierarchy: Measuring satisfaction of the needs. The American Journal of Psychology, 126, 155-177. doi:10.5406/amerjpsyc.126.2.0155

Thistlethwaite, J. (2014). Professional identity \& professionalism. The clinical teacher, 11, 234-235. doi: $10.1111 /$ tct. 12250

Torres-Rivera, E., West-Olatunji, C., Conwill, W., Garrett, M. T., \& Phan, L. T. (2008). Language as a form of subtle oppression among linguistically different people in the United States of America, Social Perspectives primavera, 10, 11-28.

Trede, F., Macklin, R., \& Bridges, D. (2012). Professional identity development: a review of the higher education literature. Studies in Higher Education, 37, 365-384. doi: 10.1080/03075079.2010.521237

U.S. Census (2010). The foreign-born population in the United States: 2010. American Community Survey Reports, ACS-19.

Walker, A. (2003). Methods, theory, and the practice of feminist research: A response to Janet Chafetz. Journal of Family Studies, 25, 990-994. 
Wilson, I., Cowin, L. S., Johnson, M., \& Young, H. (2013). Professional identity in medical students: pedagogical challenges to medical education. Teaching and learning in medicine, 25, 369-373. doi:

10.1080/10401334.2013.827968

Winefield, H. R. \& Harvey, E. J. (1996). Psychological maturity in early adulthood: Relationships between social development and identity, The Journal of Genetic Psychology, 157, 93-103. 